\title{
La historia como promesa incumplida. Hayden White, heurística y realismo figural ${ }^{*}$
}

\author{
VERÓNICA TOZZI \\ Facultad de Filosofía y Letras \\ Universidad de Buenos Aires \\ Universidad Nacional de Tres de Febrero (Posgrado) \\ veronicatozzi@fibertel.com.ar
}

\begin{abstract}
Resumen: Hayden White ofrece una manera original de entender la historización de los sucesos del pasado. La noción de Auerbach de "realismo figural" permite entender la producción de representaciones históricas realistas en términos de la presentación de una figura de la realidad. Sus reflexiones esclarecen por qué no puede alcanzarse la versión definitiva del pasado: la historia es figurada siempre por agentes en su presente e inevitablemente será reescrita una y otra vez. En clave pragmatista evocamos que la práctica científica se rige en numerosas ocasiones valorando propuestas teóricas alternativas, no tanto por su conformidad con la evidencia (algo no decidible), sino atendiendo a cuál de ellas estimula una mayor investigación. Este tipo de evaluación, denominado "evaluación heurística", resulta una forma adecuada de comprender el carácter controversial y no definitivo de la práctica de reescritura historiográfica.
\end{abstract}

Palabras clave: filosofía, epistemología, historiografía, realismo

\begin{abstract}
Hayden White offers an original way to understand the historicization of past events. Auerbach's notion of "figural realism" allows us to understand the production of realist historical representations in terms of the presentation of a figure of the reality. These reflections explain why an ultimate version of past events cannot be obtained: history is always figured by agents immersed in their present and it will be unavoidably rewritten time and time again. In a pragmatist way, we may think that scientific practice is guided in several occasions by the assessment of alternative theoretical proposals not so much because of its conformity with the evidence (something not decidable), but bearing in mind which of them suggests new paths of inquiry. The concept of "heuristic evaluation" offers an adequate way of understanding the controversial and non-ultimate character of historical rewriting practice.
\end{abstract} Key words: philosophy, epistemology, historiography, realism

*Agradezco las atentas lecturas y sagaces críticas que me han hecho el profesor Cicero Araujo (Universidad de Sao Paulo, Brasil) y los árbitros de Diánoia. 
Sobre que la historia del mundo tenga que escribirse de nuevo de tiempo en tiempo no puede caber ninguna duda en nuestros días. Pero tal necesidad no surge porque se haya redescubierto mucho de lo sucedido, sino porque se dan nuevas opiniones, porque el que disfruta de una época que progresa es conducido a un punto de vista desde el que puede abarcar y enjuiciar lo pasado de una forma nueva.

GOETHE

Es una experiencia inevitable para cualquiera que se involucra en la lectura de la historia de los sucesos del pasado el encontrarse con que tal historia está inmersa en una polémica. Notoriamente, los acontecimientos y procesos pasados nos son conocidos a través de diversas interpretaciones conflictivas. Ello nos conduce a aseverar que la aproximación a la historia de cualquier acontecimiento o proceso histórico nos sumergirá en la historia de la historia de ese acontecimiento. Esta imposibilidad de alcanzar un consenso estable ha sido considerada en general en la epistemología como un fracaso de la disciplina en su objetivo de representar realistamente lo que sucedió. Al menos dos explicaciones vienen a cuenta: 1) la inaccesibilidad o inobservabilidad directa del pasado para los historiadores que se ocupan de él; 2) el hecho de que la historia se escribe desde el presente, un momento signado, motivado por intereses diferentes y ajenos a los que rodearon los acontecimientos al momento de su ocurrencia. De este modo, siendo esos intereses cambiantes en diferentes épocas y diferentes contextos, inevitablemente cada nueva generación reescribirá su propia historia; una reescritura en sentido literal, dado que no se trata de un simple agregado acumulativo de nueva información, sino de una reorganización totalmente nueva de los acontecimientos del pasado. La nueva historia se promociona como una mejor versión de los sucesos porque permite destacar aspectos de los mismos hasta ahora soslayados o silenciados por sus competidoras, en suma, nos ofrece la promesa de acercarnos a una representación más realista de lo que acaeció.

En el presente trabajo me propongo investigar qué es lo que se promete en cada nueva reescritura del pasado, lo cual nos obligará a echar luz a esa apropiación retrospectiva que llamamos historización, cuya característica distintiva es no añorar ni sentir frustración por la imposibilidad de acceder directamente al pasado. Entre las contribuciones, hoy consideradas canónicas, a la dilucidación de la naturaleza de la representación histórica o historización se destacan las propuestas de 
los famosos filósofos de la historia William Walsh, Arthur Danto y Louis Mink, y los historiadores y teóricos de la historia Hayden White y Reinhart Koselleck. Todos ellos comparten una valoración positiva tanto del carácter retrospectivo (y nunca testimonial) de la historización, de su naturaleza controversial, así como de su inevitable reescritura en respuesta a cambios contextuales. Sin embargo, como trataré de mostrar en este escrito, ninguno de ellos supo extraer una importante consecuencia metodológica de esta sucesión de reescrituras del pasado, que formularé con carácter de hipótesis: deberá y podrá considerarse, desde una perspectiva pragmatista, como heurísticamente ${ }^{1}$ mejor aquella representación histórica de ciertos sucesos del pasado que promueva nuevas reescrituras de éstos. Esta hipótesis me fue sugerida por la particular lectura de Mimesis. La representación de la realidad en la literatura occidental, de Erich Auerbach, propuesta por White, aunque debo decir con pesar que él mismo no la pudo extraer.

Siete secciones conforman el presente artículo. Las dos primeras exponen de manera muy breve el contexto de las discusiones en la filosofía de la historia del siglo $\mathrm{xx}$, en la que aparece la obra revolucionaria de Hayden White. Las secciones tres y cuatro reconstruyen de manera profunda y detallada las contribuciones de este autor a la teoría de la historia. Mi propuesta de efectuar una valorización pragmatista y heurística de su interpretación de la reescritura de la historia se origina en los problemas particulares planteados por la historización del presente; concretamente, en torno a la cuestión de cómo la historiografía puede responder a demandas de no olvido por parte de aquellos involucrados en sucesos de carácter traumático. Las tres secciones finales se abocarán a dicha cuestión.

\section{Lo viejo y lo nuevo en la filosofía de la historia}

Desde la década de 1940 y hasta fines de los años sesenta, la discusión en torno a la estructura y justificación de las explicaciones dadas por los historiadores caracterizó la filosofía analítica ${ }^{2}$ de la historia en

${ }^{1}$ Nickles 1989, aspecto que desarrollaré en las secciones 4 y siguientes.

${ }^{2}$ La expresión "filosofía analítica de la historia" no refleja un grupo homogéneo de filósofos; sin embargo, pueden encontrarse ciertas similitudes en el tratamiento de los problemas. Las tesis que reflejan estas coincidencias, no por implicar aceptación, sino por ser objeto de polémica, son las siguientes: existe una distinción entre enunciados analíticos y enunciados sintéticos; la tarea específica de la filosofía es la búsqueda por medio del análisis conceptual de las representaciones privilegiadas, búsqueda que no se da en el ámbito de la mente, sino en el ámbito del lenguaje; 
el mundo anglosajón. Enfocarse en la noción de "explicación" como concepto clave para discutir el estatus epistemológico del conocimiento historiográfico debe en gran parte su origen al polémico artículo de Carl Hempel "La función de las leyes generales en la historia". Este trabajo, aparecido en 1942, tuvo el mérito de haber logrado que la discusión girara alrededor de la aplicabilidad o no a la historia de un modelo de explicación científica exitoso en las ciencias naturales, llamado de la cobertura legal o de subsunción nómica. Múltiples críticas a esta concepción no demoraron en asomar. En el caso específico de la historia, el debate discurrió alrededor de la necesidad de leyes generales y la exigencia de una relación lógica entre explanans y explanandum. La satisfacción de ambos requisitos garantizaba la subsunción bajo regularidades del caso que se iba a explicar (la llamada cobertura legal) y otorgaba justificación a la explicación. En otras palabras, el hecho en cuestión dejaba de ser extraño para transformarse en algo esperable de acuerdo con ciertas generalizaciones. ${ }^{3}$

Ante la evidente dificultad para formular enunciados nómicos aceptables de los fenómenos históricos, filósofos interesados en dar cuenta de la práctica histórica real, y adoptando un enfoque pragmático de la cuestión, reclamaron dilucidar la estructura y adecuación de las explicaciones dadas en historia por referencia a los intereses del historiador, evitando así imponer desde fuera un modelo ajeno a ellos. En términos metodológicos, el enfoque pragmático se tradujo en una evaluación contexto-dependiente de la corrección de las explicaciones en historia; esto es, se identifica la pregunta que pide una explicación —qué es lo que se quiere explicar-, o con respecto a qué el suceso resulta enigmático como para requerir explicación. La adecuación o pertinencia de la explicación dependerá de si responde o no a la pregunta formulada; en definitiva, su corrección no puede evaluarse por su conformidad con un modelo pensado para responder a intereses y objetivos de otros campos de estudio. El pluralismo explicativo fue el resultado positivo de esta contienda. Irónicamente, señala Arthur Danto, poco después, en lugar de que la historia fuera atada al cuerpo más amplio de la ciencia por un Anschluss lógico, las ciencias naturales mismas fueron puestas en cuestión (gracias a trabajos como los de Kuhn, Hanson y Toulmin, entre otros) por las mismas "dificultades", antes consideradas exclusivas de las ciencias humanas.

la filosofía descubre la forma lógica o estructura gramatical profunda a partir del análisis del lenguaje (ideal o natural); la epistemología (la teoría del conocimiento) domina la ontología.

${ }^{3}$ Para una relación completa de la discusión, véase Danto 1985, cap. X. 
La década de 1970 atestigua el arribo del giro lingüístico a la filosofía de la historia, dando lugar a lo que, siguiendo a Ankersmit (1986), llamamos hoy nueva filosofía de la historia. En ella, la noción de explicación, como concepto clave para dar cuenta del estatus del conocimiento histórico, es desplazada por el concepto de narración; esto es, ya no se indaga en la estructura lógica de las explicaciones dadas por el historiador, sino acerca del estatus cognitivo de las interpretaciones históricas en cuanto discurso cuyo sentido y aceptabilidad es irreductible a los enunciados singulares que lo componen. Este desplazamiento de preocupaciones y problemas se dio en forma paralela al giro lingüístico y al giro histórico-pragmático en la filosofía de las ciencias. El primero, el giro lingüístico, se caracteriza por un interés en los instrumentos lingüísticos en sí mismos; el segundo, el giro histórico-pragmático, aboga por investigaciones concretas de por qué los historiadores, en un contexto determinado, prefieren una interpretación a otra. Al igual que en el debate sobre explicación, las posiciones en torno a la narrativa histórica son muchas y variadas, desde concepciones que encuentran una continuidad entre el lenguaje y el pensamiento del historiador, por un lado, y el lenguaje y el pensamiento de los actores sociales, por otro - continuidad que permite fundar algún tipo de realismo-, hasta una concepción que considera que la propia forma narrativa ejerce una imposición distorsionadora sobre el pasado real. Dos aspectos de la nueva filosofía de la historia deben destacarse en relación con el tema de este artículo: por un lado, al liberarse de discutir en términos de su relación con las ciencias naturales, se atiende con mayor profundidad y detalle aquello que es lo específicamente histórico; por el otro, abre el espacio para que una diversidad de tradiciones (fenomenología, hermenéutica, pragmatismo y hasta la nueva filosofía de las ciencias) y de disciplinas (teoría del arte y teoría literaria, al menos) participen en dicha tarea. En la línea de estos desarrollos se enmarca el presente trabajo.

\section{En la búsqueda de algo más que información}

En un conocido ensayo, ascéticamente titulado "Oraciones narrativas", Danto aborda los clásicos problemas de la filosofía de la historia a través del análisis de ese tipo particular de expresiones: "que se refieren a dos acontecimientos, al menos separados en el tiempo, aunque sólo describen (versan sobre) el primero de ellos, esta descripción y referencia se hace de un modo que jamás podría hacerlo un testigo contemporá- 
neo". ${ }^{4}$ Lo que Danto trata de destacar es que nadie podría afirmar con verdad en 1642, al presenciar el parto de un niño en una pequeña casa de Wolethorpe: "Aquí y ahora nace el autor de los Principia", ni tampoco podría alguien haber afirmado en 1648: "Desgraciadamente comienza la Guerra de los Treinta Años." La prohibición se debe no sólo al hecho de que la descripción toma en cuenta algo que aún no sucedía, sino (todavía más importante) al hecho de que la selección de los sucesos posteriores con los cuales se describirá el suceso en cuestión dependerá también de una perspectiva posterior, absolutamente vedada a un testigo contemporáneo. Esto nos permite acompañar a Danto en su conclusión de que cualquier organización temporal de acontecimientos pretéritos - sean estructuras diacrónicas o sincrónicas- no se reduce al establecimiento de una magra conexión serial entre ellos, sino que en ella interviene la categoría de significación. No sólo se busca establecer relaciones temporales, causales o del tipo que sea entre los sucesos, sino relaciones significativas; esto es, que respondan a las preguntas e intereses cognitivos de alguna comunidad de historiadores en particular. En esta misma línea reflexiva, Walsh y Mink, interesados en la especificidad de la representación histórica, han intentado describir este plus que la caracteriza en contraste con la mera sucesión cronológica y que le es posible justamente por realizarse con posterioridad a la ocurrencia de los sucesos. Mink ha denominado comprensión figural a este tipo particular de comprensión efectuada por la historiografía, con el fin de destacar su carácter holístico o gestáltico. A diferencia de la mera crónica, que podría limitarse a registrar sucesos a medida que ocurren, el historiador, necesariamente con posterioridad, trata de ver unido en una totalidad lo que estaba separado en la mera sucesión. ${ }^{5}$ Más tempranamente, Walsh había introducido el neologismo "coligación" para describir el procedimiento de explicar un acontecimiento rastreando sus relaciones intrínsecas con otros acontecimientos y de localizarlo en su contexto histórico con el propósito de formar un todo coherente. El trazado de conexiones entre sucesos dispersos nos permite mostrar cómo los hechos detallados se hacen inteligibles y pueden configurarse en un relato que los haga significativos (Walsh 1968, pp. 66-67).

En forma humorística, pero no por eso menos sofisticada, Koselleck evoca la advertencia de Gentz acerca de si Luis XVI fue castigado, ejecutado o asesinado, como la verdadera cuestión histórica, cuestión no dirimible ni reducible a la descripción de si una guillotina de un tipo

\footnotetext{
${ }^{4}$ Véase Danto 1989, p. xi.

5 "Modes of Comprehension and the Unity of Knowledge", en Mink 1987, p. 39.
} 
particular separó su cabeza de su cuerpo. ${ }^{6}$ Siendo fieles y estrictos a los problemas con que se enfrentan los historiadores, podríamos decir junto con Koselleck que aquellas cuestiones que tienen que ver con la autenticidad de los documentos, su datación, la manipulación de datos estadísticos, los tipos de lectura y variantes de textos, su recepción y desarrollo, en suma, todas aquellas prácticas dirigidas al establecimiento de la información disponible acerca del pasado, son controlables empíricamente. Este quehacer no es muy distinto de las técnicas experimentales de las ciencias naturales; esto es, constituye una práctica para la cual los historiadores se entrenan y sus resultados están disponibles a cualquiera en el sentido de ser comunicables, reiterables y revisables. Sin embargo, aun cuando toda esta información documental pone límites a lo que podemos decir o a la historia que podemos contar o al análisis que queramos hacer, no nos da ninguna orientación de lo que específica y acertadamente deberíamos decir. Si los historiadores buscan explicar, por ejemplo, una crisis o una guerra, ya sea como resultado de un cálculo erróneo de las fuerzas, ya sea en términos psicológicos, económicos o de otro tipo, ninguna de estas cuestiones podrá decidirse en el plano de las fuentes. Éstas son necesariamente decisiones teóricas. ${ }^{7}$

En la misma línea argumentativa, White, mi autor preferido en la filosofía de la historia por lograr expresar del modo más contundente y sintetizador todas estas intuiciones, distingue las cuestiones de tipo archivístico o informacional, disponibles a cualquier disciplina, de la actividad de transformar esa información en histórica, un tipo especial de discurso que logre interpretar significativamente esa información. Esta última tarea, sugiere White, exige apelar a estrategias de figuración que hagan que la mera cronología se manifieste como un todo coherente y significativo. ${ }^{8}$ Con esta preocupación en mente, el autor instará a echar mano de todas aquellas investigaciones teóricas que han tomado al discurso como objeto de análisis, principalmente la teoría literaria, para que ilumine esa actividad de configuración del pasado que ya lleva más de dos mil años y que alcanza su apogeo y profesionalización en el siglo XIX, actividad caracterizada por dar algo más, o tal vez mucho más, y siempre cada vez más que mera información y que llamamos historia. Concretamente, White develará el plus del discurso histórico sobre la información en términos estético-figurativos o tropológicos. Ahora bien, dado el carácter presentista de la historización, cada nueva generación

\footnotetext{
${ }^{6}$ Véase "Compromiso con la situación y la temporalidad", en Koselleck 1993, p. 199.

${ }^{7}$ Véase Koselleck 1993, p. 201.

${ }^{8}$ Véase “Teoría literaria y escrito histórico”, en White 2003a, pp. 142-143 y 155.
} 
se encontrará a su vez con la posibilidad de buscar nuevas conexiones significativas en la información.

Un mismo modo de concebir la historización encontramos en el tratamiento de Danto de las oraciones narrativas, en la explicación por coligación de Walsh, en la comprensión figural de Mink, en las reflexiones teórico-perspectivistas de Koselleck y en las tropológicas de White. La coincidencia puede elucidarse a través de la formulación de cuatro actitudes o asunciones teóricas características:

1) se privilegia la adopción de una mirada al pasado comprometida conscientemente con los intereses del contexto presente del historiador, esto es lo que se denomina retrospectiva. Los intereses pueden tomar la forma de preguntas teóricas que se le formulan al pasado;

2) el objetivo de esta apropiación retrospectiva es el establecimiento de relaciones entre acontecimientos considerados reales (es decir, opuestos a ficticios o míticos), de los cuales se tiene noticia indirectamente, inferencialmente a través de la evidencia;

3) el propósito de la mirada retrospectiva sobre la información obtenida a través de la evidencia es el establecimiento de algún esquema de organización, el cual puede proponer indistintamente una narrativa o la identificación de una estructura epocal o un proceso a gran escala. Cualquiera sea la configuración elegida, todas se caracterizarán por agregar algo o decir algo más de lo que puede ser dicho con el sólo hecho de simplemente registrar la información o los acontecimientos. La producción de este plus deja a los historiadores sin normativas que exijan o muestren que un tipo de organización es más adecuado que otro basándose sólo en la iteración de la información, sin referencia al punto de vista desde el que se hace la organización; 9

4) se asume la dificultad de llegar a un acuerdo diacrónico o sincrónico sobre cuál es el mejor esquema de organización. En la medida en que los intereses se renuevan y cambian, asistimos a sucesivas reescrituras y reorganizaciones de los acontecimientos del pasado.

Ahora bien, no obstante estas coincidencias, debemos advertir que esta idea de la historia como reescritura de la historia - la cuarta asunción — no ha sido apreciada en todo su potencial cognitivo, dado que no

${ }^{9}$ No se trata de negar la dificultad involucrada en el establecimiento de los hechos o en la evaluación de la confiabilidad de los instrumentos informacionales acerca del pasado: fuentes, documentos, etc., pero seríamos ciegos a la comprensión que nos da la historia si la redujéramos al trabajo con las fuentes.

Diánoia, vol. LI, no. 57 (noviembre 2006). 
se ha extraído lo que para mí es su consecuencia fundamental: que cada nueva reescritura de la historia es una respuesta, desde el presente, a reescrituras promovidas por alguna historia anterior de los mismos sucesos. ${ }^{10}$

El fin que guía este trabajo es darle espesor a dicha consecuencia reelaborando las tesis extraídas por White a partir de su atenta lectura de la historia de Auerbach del realismo literario occidental, una historia trazada en términos de una concepción denominada "realismo figural". Pero antes me detendré en la obra de White con el objeto de hacer ciertas aclaraciones que prevengan malas interpretaciones.

\section{La preparación del campo histórico}

Debemos reconocer que gracias a Metahistoria. La imaginación histórica en el siglo diecinueve, hoy contamos con un estudio sistemático y de amplio alcance de los "recursos lingüísticos" que intervienen en la producción de relatos históricos, así como con una explicación profunda de la dificultad, hasta imposibilidad, de resolver las controversias historiográficas. En su ensayo introductorio, White nos advierte del hecho de que, para poder constituir un discurso acerca del pasado como histórico, el historiador previamente debe prefigurar el campo histórico, ${ }^{11}$ denominación con la que hace referencia al registro documental anterior al análisis y la conceptualización. Esta operación, señala, es de carácter tropológico; esto es, no es resultado de ningún proceso inferencial, no hay reglas lógicas que obliguen, a partir del registro evidencial, a adoptar una forma de conceptuar en lugar de otra. Éstas son más bien adopciones poéticas a partir de las cuales quedarán permitidos ciertos tipos de relaciones entre ciertas categorizaciones de agencia y circunstancias. Los recursos disponibles para hacer conceptualizables dichos elementos "brutos" nos son provistos por el uso lingüístico mismo, pues el acto de prefiguración será entendido a partir de los cuatro tropos básicos para el análisis del lenguaje figurativo: metáfora, metonimia, sinécdoque e ironía. Concretamente, la metáfora sancionará las prefiguraciones del mundo de la experiencia en términos de objeto-objeto, la metonimia en términos de parte-parte, la sinécdoque

\footnotetext{
${ }^{10}$ Siendo más estrictos, deberíamos decir, "historia anterior del mismo tipo de sucesos" más que de los mismos sucesos. En la medida en que la historiografía es una empresa propia de una disciplina, nadie hace investigación histórica ex nihilo; siempre se emprende la investigación, aún de sucesos todavía no historizados, desde algún programa, paradigma, tradición o escuela de investigación.

${ }^{11}$ Véase White 1992, p. 25, n. 8.
} 
en términos de parte-totalidad, mientras que la ironía, considerada un metatropo, afirmará en forma tácita la negación de lo afirmado positivamente en el nivel literal. Esta prefiguración constituye, podríamos decir, la infraestructura del texto histórico; es decir, el campo histórico se constituye como un dominio sobre el cual el historiador puede aplicar, del modo más coherente posible, sus creencias ideológicas, sus concepciones epistemológicas o sus preferencias narrativas.

El resto del libro nos proporciona una aplicación de dicho aparato conceptual al análisis de cuatro grandes historiadores y cuatro grandes filósofos de la historia del siglo XIX. ${ }^{12}$ Las historias de Michelet, Ranke, Tocqueville y Burkhardt y las filosofías de la historia de Hegel, Marx, Nietzsche y Croce son examinadas para dejar al descubierto en sus escritos un nivel preconceptual, de carácter intrínsecamente estético o figurativo, determinante del nivel conceptual explícito. Es decir, tanto los compromisos explícitos de carácter teórico-epistemológico y político-moral, así como las elecciones entre diferentes técnicas narrativas para tramar los acontecimientos pasados, se correlacionan en la obra de estos grandes autores, implícita y determinantemente, con alguno de los tropos. Me gustaría expresar que uno de los logros más destacados del estudio whiteano reside en haber revelado el esfuerzo de cada uno de estos autores por conciliar entre sí los compromisos epistemológicos, narrativos e ideológicos sugeridos por su preferencia tropológica, conciliación que no siempre resulta exitosa en términos de coherencia. En otras palabras, el abordaje metahistórico detallará justamente las dificultades a las que se enfrentaron estos grandes pensadores para coordinar las diferentes dimensiones que conforman un discurso histórico, coordinación que no viene dictada por el registro, sino que es un trabajo que realizar. Dos importantes consecuencias se nos es permitido extraer a partir de estas sugerencias. En primer lugar, estamos ahora en condiciones de explicar las diferencias primordiales entre relatos históricos rivales: lo que los hace irreconciliables no proviene de haber seleccionado diferentes hechos, ni de haber adoptado diferentes concepciones metodológicas o epistemológicas, ni siquiera en sostener diferentes compromisos ideológicos o haber elegido diferentes técnicas de narración. Lo que los distingue e impide su conciliación es resultado del acto precrítico y constructivo de prefiguración tropológica. En segundo lugar, estamos también en condiciones de apreciar positivamente las dificultades enfrentadas por estos autores para lograr un cierre definitivo y coherente sobre el tema del que se ocupan, oca-

${ }^{12}$ Debe advertirse que la introducción fue escrita al finalizar el libro. 
sionando que sus modos o estilos de mirar al pasado sigan vigentes. Esta última es la sugerencia desarrollada más profundamente en Figural Realism; pero antes de sumergirnos en ella será importante rescatar algunas observaciones aclaratorias de su proyecto expresadas en su reciente "Hecho y figuración en el discurso histórico". ${ }^{13}$

La obra de White ha sido leída por sus críticos ya sea como si negara la existencia pasada de aquellos acontecimientos, personas, procesos, grupos e instituciones de la que hablan los historiadores, ya sea como si les otorgara sólo una existencia lingüística. Lo que ha soslayado esta lectura es la intención de White de llamar la atención sobre el carácter problemático y el esfuerzo requerido cuando se toma la decisión, tal como él mismo dice, en torno a "cómo hemos de llamar a estos fenómenos, cómo hemos de clasificarlos y qué tipos de explicación hemos de ofrecer de ellos" (White 2003a, p. 51). El trabajo historiográfico consiste en la construcción - en el sentido de imaginar y conceptuar- de sus objetos de interés antes de poder proceder a aplicarles los tipos de procedimientos que desea usar para explicarlos o comprenderlos como posibles temas de una representación específicamente historiológica. ${ }^{14}$

Yo sé que "el Imperio Romano", "el papado", "el Renacimiento", el "feudalismo", "el Tercer Estado", "los puritanos", "Oliver Cromwell", "Napoleón", "Ben Franklin", "la revolución francesa", etc., o al menos las entidades a las que estos términos hacen referencia, preexistieron a cualquier interés por ellos de algún historiador dado. Pero una cosa es creer que una entidad alguna vez existió, y otra completamente distinta constituirlo como un posible objeto de un tipo específico de conocimiento. Esta actividad constitutiva es, creo, una cuestión de imaginación tanto como de conocimiento (White 2003a, p. 52).

En el mismo espíritu, debe señalarse que, a lo largo de toda su obra, White nunca intentó promover un determinismo lingüístico, sino subrayar el hecho de que, una vez embarcados en el análisis de cualquier tipo de escrito, debemos "tener en cuenta las formas en que el uso de los diversos códigos, de los cuales el lenguaje es en sí mismo un paradigma, capacita tanto como limita aquello que puede decirse acerca del mundo". ${ }^{15}$ Cuando White afirma que los hechos históricos son inventados, sólo quiere advertirnos que asumamos seriamente (y no retóricamente) que los hechos no nos vienen "dados" ni están ya almacenados como "hechos" en el registro documental.

\footnotetext{
${ }^{13}$ Prefacio de White 2003a.

${ }^{14}$ Véase White 2003a, pp. 44-45.

${ }^{15}$ White 2003a, pp. 46-47, las cursivas son mías.
} 
En definitiva, los trabajos de White (sobre todo Metahistoria y "El texto histórico como artefacto literario" (White 2003a)) han sido leídos apuntando al carácter ficticio de la historiografía. En el presente trabajo y a la luz de los textos posteriores de White, ${ }^{16}$ sugiero, por el contrario, leerlo como un texto que llama la atención acerca de que lo que ha de ser una representación realista del pasado es algo que ha de hacerse de acuerdo con las convenciones lingüísticas disponibles.

El realismo figural —inspirado en Auerbach - nos muestra, por un lado, hasta qué punto la tesis de que la historia es una construcción no significa otra cosa que subrayar el esfuerzo que involucra la composición de un discurso histórico relevante y significativo. Pero, por otro lado, estas reflexiones de White nos ofrecen una guía en el análisis de la relación entre diferentes representaciones realistas de los mismos fenómenos históricos: no como una sucesión de descripciones que se acercan cada vez más a la verdad o al pasado en sí, aunque siempre fracasan en su empeño, sino como sugerencias de mayor investigación y nuevas reescrituras históricas. Podremos decir que en cada nueva reescritura no presenciamos el cumplimiento de una mejor representación de la realidad; más bien deberíamos decir que con cada reescritura de la historia se nos renueva una promesa de cómo alcanzar mejores representaciones de la realidad. Éste es el sentido en el que decimos que cada reescritura es una respuesta a escrituras precedentes.

\section{El realismo como promesa}

En "Auerbach's Literary Theory. Figural Causation and Modernist Historicism" (1999b), White dice encontrar en la historia de la literatura de este autor (Auerbach 1950) un concepto apropiado de realismo: el "realismo figural", no sólo para la historia literaria, sino para la historia en general. El interés que sigue despertando Mimesis reside en el hecho de que Auerbach, a través del análisis de diferentes obras de la literatura occidental desde Homero hasta el modernismo literario de Woolf y Proust, describe, por un lado, cómo cada una de ellas ha propuesto conexiones entre los acontecimientos para representarlos adecuadamente $y$, por el otro, las conexiones que se establecen en estos sucesivos intentos de representación. Es por ello, señala White, que Mimesis es tanto una historia del realismo literario occidental, como un intento de producir una concepción de lo que es una historia de sucesivas formas de

${ }^{16}$ Como en "La trama histórica y el problema de la verdad" (pp. 189-216) y "Hecho y figuración en el discurso histórico" (pp. 43-61), en White 2003a, analizados en el presente artículo. 
representar. ${ }^{17}$ La noción que rige y se revela en la historia que Mimesis relata es la de "figura" o "interpretación figural", mediante la cual se "establece una relación entre dos acontecimientos o personas, por la cual, uno de ellos no sólo tiene su significación propia, sino que apunta también al otro, y éste, por su parte, asume en sí a aquél o lo consuma [involves or fulfills the first]" (White 1999b, p. 74).

Figuralmente es como se conecta el Renacimiento italiano con la cultura grecolatina, considerando a ésta como si apuntara hacia el Renacimiento y a éste como si consumara aspectos de la primera. En la misma tónica, el Nuevo Testamento es para los cristianos como un cumplimiento o consumación de las Antiguas Escrituras. Finalmente, en El 18 Brumario de Luis Bonaparte, Marx otorga significado a la revolución de 1848 como una consumación de la de 1789, y a ésta como si apuntara, figurara, lo que sucedió en 1848. Por otra parte, la revolución de 1789 puede haber sido un efecto de la Reforma protestante y del iluminismo y, como tal, el final de un proceso más que la prefiguración de acontecimientos por venir. Sin embargo, como acontecimiento histórico, permanece abierto a la apropiación retrospectiva que cualquier grupo pueda hacer, eligiéndolo como prototipo legitimante de su propio proyecto de constitución (White 1999b, p. 96). En términos específicos, el acontecimiento pasado es visto retrospectivamente por algún grupo posterior como una figura, y los sucesos posteriores con los que se lo relaciona desde el presente son vistos como la consumación o cumplimiento de lo figurado en el anterior.

Lo que se expresa en estas consideraciones y motiva a seguir a White y apropiarnos de ellas como justa consideración de lo que sería un "realismo histórico" reside en la propuesta de tres prescripciones metodológicas. La primera, tomar las representaciones de la realidad (literarias o históricas) como una propuesta de mirar bajo otro aspecto los acontecimientos pasados, nos insta a asumir otra perspectiva con la promesa de que con esta nueva mirada la realidad se verá mejor. La segunda plantea que estas propuestas son hechas siempre desde algún contexto (disciplinar y/o político) y es el contexto el que legitima la significa-

${ }^{17}$ En esta misma línea, Ankersmit, en "Why Realism? Auerbach on the Representation of Reality" (Ankersmit 2001, pp. 197-217), destaca que la investigación de Auerbach implica que el realismo sólo puede ser definido por medio de una historia del realismo, sólo existe en las muchas variantes en las que se ha mostrado a sí mismo en el curso de su larga historia (véanse las pp. 197-198). En este sentido diremos que podremos apreciar cómo la historia representa la realidad pasada sólo a través de su propia historia. Es decir, sólo podremos concebir el realismo histórico desde una aproximación historicista a la propia historiografía. 
ción alcanzada. La tercera consiste en que las diferentes propuestas se relacionan entre sí figuralmente, y esto será síntoma de fertilidad metodológica. Auerbach mismo relacionará figuralmente los diversos y sucesivos realismos de la literatura occidental, como cuando describe el realismo de Balzac como el cumplimiento de la promesa de representación del realismo de Dante. En síntesis: el realismo figural nos permitirá explicar, en primer lugar, la relación entre las representaciones históricas de la realidad y la realidad; en segundo lugar, la relación entre una representación y su contexto, y en tercer lugar, la relación entre las sucesivas representaciones mismas. Detallaré a continuación cada una de estas apropiaciones metodológicas.

En el primer caso, siguiendo a White, esta relación figural entre acontecimientos nos permite hablar legítimamente de un "realismo figural", subrayando que si bien estamos registrando acontecimientos, no hacemos simplemente eso, sino que los relacionamos significativamente; por lo cual esa relación es una construcción, en el sentido de que dice de ellos algo más y no dice todo lo que se podría decir. Textualmente, Auerbach afirma que

Los dos polos de la figura están separados en el tiempo, pero, en tanto que episodios o formas reales, están dentro del tiempo; ambos están contenidos en la corriente fluida de la vida histórica, pero la comprensión, el intellectus spiritualis, de su conexión es un acto espiritual. (White 1999b, p. 75)

En otras palabras, mediante la representación figural, los acontecimientos pasados se relacionan con acontecimientos presentes bajo la idea de "cumplimiento" o consumación (fulfillment). ${ }^{18}$ De este modo, se sugiere mirar los acontecimientos como si esperaran alcanzar en algún futuro, y en relación con otros acontecimientos, su plena significación pero siendo este objetivo nunca definitivamente realizable ni siquiera especificable. White nos insta a comprender la representación figural en analogía con el cumplimiento de las promesas: podemos deducir retrospectivamente que alguien hizo una promesa si ese alguien la cumplió, pero el cumplimiento no puede ser inferido prospectivamente del

\footnotetext{
${ }^{18}$ La noción de fulfillment le permite endosar a la historia el significado de un progreso hacia un objetivo que nunca es finalmente realizable ni aún completamente especificable. Le asigna un concepto de causación peculiarmente histórico, diferente de las nociones teológicas antiguas, por un lado, y de las nociones mecanicistas de la ciencia moderna, por el otro. Este modo distintivamente histórico de causalidad, White propone llamarlo causalidad figural (véase White 1999b, p. 88).
} 
acto de prometer. Un acontecimiento histórico aparentemente aislado puede adquirir un nuevo significado al ser relacionado con otro posterior presentándolo como una promesa de cumplimiento, esto es, como si prometiera consumar su significación.

Esto nos lleva directamente a la segunda apropiación metodológica, a la que se ocupa de la relación entre la representación y su contexto, pues estas propuestas o promesas de nueva significación se hacen desde alguna perspectiva y no hay ninguna necesidad objetiva o trascendente de hacerlas. Al igual que en la lectura renacentista de la cultura grecolatina, señala White, el lazo no es causal, no hay necesidad de ligar estas dos culturas, sino que es fruto de una decisión. El lazo tampoco es genético; esto es, su inclusión en una misma secuencia histórica no tiene fundamentos objetivos. Finalmente, señala White, "el lazo no es teleológico: el fin, producir una figura definitiva de los acontecimientos, jamás es alcanzado". Esto merece una aclaración. El realismo figural no niega que la historia (ya no la literaria, sino la historia en general) pueda establecer relaciones causales o genéticas; es decir, secuencias temporales objetivas. Sólo señala que esa tarea aislada es incompleta e irrelevante. De lo que se trata es de construir figuras: relaciones relevantes desde alguna perspectiva, lo cual supone que la selección de una secuencia o el trazado de alguna línea genética en lugar de cualquier otra secuencia o trayectoria temporal es un acto de decisión. Hay muchas secuencias posibles que podemos asumir y en cada una destacaremos o llamaremos la atención sobre diferentes formas de presentar la realidad desde diferentes perspectivas. ${ }^{19}$ En conclusión, dice White, como toda figura es una construcción y la representación histórica es una figuración, toda representación histórica de la realidad es también una presentación. ${ }^{20}$

Finalmente, la propia relación entre representaciones sucesivas de los acontecimientos que se dirijan a destacar diferentes aspectos de los mismos, la tercera apropiación metodológica, resulta también iluminada en términos del realismo figural. Es decir, los aspectos destacados por las representaciones posteriores tienen una función explicativa de los destacados por las representaciones anteriores, en el sentido de que

${ }^{19}$ El origen de este realismo figural está en San Agustín, defensor del carácter histórico de la realidad de las figuras frente a aquellas corrientes alegóricoespiritualistas, las cuales socavan el carácter realista del acontecer, viendo en éste tan sólo signos y significaciones extrahistóricas (véase Auerbach 1950, pp. 186187).

${ }^{20}$ Idea basada en las interpretaciones cristianas del judaísmo antiguo como anticipación de la cristiandad (White 1999b, p. 94). 
las posteriores tratan de cumplir promesas incumplidas por los anteriores, renovando la promesa de alcanzar la representación. En términos de White: "el modelo figura-cumplimiento ofrece el guión diacrónico de la historia de la literatura occidental como una relación genealógica de expropiaciones sucesivas de presentaciones de la realidad". ${ }^{21}$

En definitiva, el "realismo figural", con su descripción de la operación de historización como promesa siempre renovada de ofrecer una representación realista del pasado, más que el cumplimiento definitivo de la misma, nos permite tener una valoración positiva de la reescritura de la historia. Esta finalidad no alcanzada, pero siempre prometida, es lo que permite explicar por qué no puede, ni tampoco importa, que se alcance la versión definitiva de los acontecimientos pasados. Sin embargo, que cada nueva representación pueda renovar la promesa de cumplimiento es un signo de su éxito, al dejar cuestiones abiertas para ser tomadas por otros. Cada historia es figurada siempre por agentes en un presente y el éxito de su figuración reside en ofrecer promesas que cumplirán o desafíos que asumirán otros desde sus propios contextos. En clave pragmatista, podemos evocar que la práctica científica se rige en numerosas ocasiones valorando propuestas teóricas alternativas, no tanto teniendo en cuenta la mayor conformidad con la evidencia (algo no decidible de modo definitivo), sino atendiendo a cuál de ellas ofrece más interrogantes y nuevas vías de investigación. Este tipo de evaluación, identificado en estudios concretos de los procesos de producción de teorías científicas, ha sido denominado por Thomas Nickles "evaluación heurística", y nos provee el modo adecuado de comprender el carácter controversial y no definitivo de la práctica de reescritura historiográfica. ${ }^{22}$ En suma, mi mirada pragmatista del realismo figural permite

${ }^{21}$ White 1999b, p. 91. El esquema cristiano de la figura y su cumplimiento (usado por los pensadores cristianos para interpretar la relación entre el Viejo Testamento y el Nuevo, entre el judaísmo y la cristiandad, entre este mundo y el de más allá, entre el presente y el futuro, y en Dante aún entre el paganismo y la cristiandad) es asido por Auerbach como una figura misma que será cumplida en la moderna idea de historia. Indudablemente, Auerbach sostiene que la historia es precisamente ese modo de existencia en el que los acontecimientos pueden ser al mismo tiempo cumplimientos de acontecimientos anteriores y figuras de posteriores. Tal esquema caracteriza la particular combinación de la novedad y la continuidad que distingue la existencia histórica de la natural (véase White 1999b, p. 95).

${ }^{22}$ Nickles (1989) introduce la noción de evaluación heurística (heuristic appraisal), para distinguirla de la evaluación epistémica (epistemic appraisal), que ha sido el foco de interés de los filósofos, con el fin de diferenciar la práctica de juzgar los méritos de una teoría por su registro pasado de éxito o fracaso predictivo, de la práctica de valorarla positiva o negativamente por abrir nuevas áreas de investiga-

Diánoia, vol. LI, no. 57 (noviembre 2006). 
apreciar, no sólo que la verdad y la significación de los acontecimientos del pasado solamente puede conocerse después de su ocurrencia (como señalara acertadamente Danto), sino que lo que hace verdaderamente significativa una representación es su valor heurístico; esto es, que nos legue cuestiones abiertas como para que merezca volver sobre ellos o valga la pena reescribir su historia.

\section{La política de la reescritura de la historia}

El valor heurístico de la concepción de la historización como figuración realista del pasado se probará en toda su expresión en el análisis de las consecuencias políticas que se derivan de historizar el presente. Volviendo a White, la doctrina del historicismo es la clave para entender la historia del realismo occidental, donde no sólo se reconoce que toda mirada histórica se hace desde el presente, sino que el propio presente es mirado históricamente. Con este propósito intentaré mostrar cómo su lectura del "realismo figural" podría responder, aunque de modo contrario al que él mismo pretendería, a los problemas originados en la dificultad de representar históricamente los acontecimientos traumáticos recientes, en particular aquellos que, por su carácter de extrema violencia, mantienen abiertas heridas, haciendo difícil, si no imposible, llegar a un acuerdo en su interpretación. Sucesos tales como el Holocausto, las dos guerras mundiales, las guerras étnicas, el hambre a escala nunca vista, imponen al historiador ciertos límites a las interpretaciones que haga de ellos, exigiendo evitar aquellos tipos de representaciones que, al hacerlos comprensibles, atenúen justamente su carácter extremo. Cualquier representación orientada a hacer inteligibles estos sucesos debe evitar eliminar la fuerza y verdad del horror que los sobrevivientes realmente enfrentan y tratan de transmitirnos. En otras palabras, la cuestión es cómo abordamos su experiencia sin bastardearla o reducirla a un cliché. Sorprendentemente, estos acontecimientos testifican el hecho paradójico de partida de la disciplina histórica, por ser acontecimientos de los que se tiene y se puede tener gran cantidad de información confiable, al tiempo que su marca más destacable es la imposibilidad de alcanzar acuerdos en cuanto a su significado o interpretación. ${ }^{23}$

ción para aquellos miembros de la comunidad científica que ya han invertido en ella (véase la p. 176).

${ }^{23}$ Para un detallado análisis de los límites de la representación, véase Friedlander 1992, y LaCapra 2001. Me he ocupado extensamente de estos debates en diversas publicaciones recientes indicadas en la bibliografía. El papel de la perspectiva de la 
Similares dificultades y análogas reflexiones provienen de los desafíos lanzados a la historiografía académica por parte de numerosos movimientos de derechos civiles en el siglo xx, inspirados en el multiculturalismo, el feminismo y los procesos de descolonización. El reclamo de los militantes de estos movimientos de ser ellos los autores de la reconstrucción histórica de los sucesivos padecimientos de distintos grupos, sometidos por largos periodos del pasado a diferentes vejaciones, opresiones y discriminaciones, se basa también en la exigencia de que su interpretación no obnubile la extrema experiencia de las víctimas a través de algún artificio contextualizador del tipo de la apelación a las condiciones o fuerzas históricas que obligaron o al menos posibilitaron su ocurrencia. En estrecha sintonía con la demanda de autoría, entendemos el cuestionamiento de la legitimidad de la historiografía académica en la producción de estas representaciones.

Lo que se cuestiona a la historiografía académica tradicional es que, en su esfuerzo por ser objetivos, imparciales y respetar la evidencia, los historiadores adoptan un tipo de historización totalizante, pretendidamente superadora de todas las parcialidades (incluso la propia) intentando dar la impresión de clausura significativa, lo cual deja entrever un anhelo por las versiones definitivas del pasado. Nuestra lectura heurística del realismo figural whiteano nos provee un antídoto contra estas pretensiones clausurantes; sin embargo, para que esto se haga evidente debemos enfrentar dos últimas cuestiones. La primera es qué tipo de pluralismo y oposición a la clausura se promueve en mi visión heurística del realismo figural. La segunda, qué papel cumple la experiencia de las víctimas en la historización y cómo se ha de incluir su voz en la visión del pasado reciente.

\section{Pluralismo, desobediencia crítica y reescritura}

Si bien he mostrado a lo largo del trabajo que la reescritura de la historia es inevitable y que los más notables teóricos de la historia e historiadores han valorado positivamente esta marca notoria de la historiografía, debemos, no obstante, precisar más la función que cumple o debería cumplir cada nueva reescritura del pasado. En la respuesta quedará en evidencia el espíritu pragmatista de mi lectura, la cual, a partir de la función precautoria de evitar clausuras significativas distingue entre la adopción de una actitud heurística que promueva aquellas reescrituras

víctima en la producción de la representación adecuada se analizará en la última sección. 
que estimulen mayor investigación, y la actitud parasitaria de la historiografía académica y posiblemente abortiva en cuanto al desarrollo de programas de investigación. Esta última es la actitud elegida por Keith Jenkins en su reciente Refiguring the Past (2003). Dos razones me obligarán a detenerme con cierto detalle en las reflexiones de este autor. En primer lugar, por declararse un fiel, si no el más fiel, seguidor de la posición whiteana, y, en segundo lugar, por generar una lectura vulgarizada de su obra que la ha expuesto a la critica fácil, con la consecuencia indeseable de oscurecer y por ello impedir la difusión de las importantes contribuciones heurísticas que su obra ha tenido para la práctica de la disciplina historiográfica. ${ }^{24} \mathrm{Si}$ bien es un viejo opositor a cualquier atisbo de clausura interpretativa y da la bienvenida al pluralismo, ello no involucra que cualquier tipo de pluralismo le resultará política y epistémicamente aceptable. Jenkins estimula procedimientos de desobediencia crítica radical que, en contra de la mayoría de los análisis históricos, no aspiren a resolver las disputas históricas, sino que celebren el fracaso de todas. Explícitamente, convoca a desobedecer las voces autoritarias y "remplazar cualquier clausura definitiva con una apertura interminable y cualquier fin agotado con un et cetera" (Jenkins 2003, p. 6). Jenkins quiere diferenciarse del pluralismo interpretativo que abrazan hoy muchos historiadores, pues, según él, continúan atrapados en la búsqueda del conocimiento histórico real, la objetividad y la consideración sinóptica basada en la evidencia; en otras palabras, siguen atados al ideal de alcanzar clausuras efectivamente interpretativas.

El "argumento" tiene como punto de partida la asunción de la imposibilidad de alcanzar tal interpretación definitiva, lo que involucra, según Jenkins, una apertura inevitable para nuevas, irrespetuosas y radicales lecturas y relecturas, escrituras y reescrituras del pasado. Ahora bien, las razones para esta deseable refiguración ad infinitum son informadas por un pensamiento abiertamente político, aunque también por su visión teórica: ${ }^{25}$

la identidad que los sujetos habitan siempre es temporaria [...] lo que constituye el sujeto humano es el resultado de procesos dinámicos denominados iterabilidad (el proceso de repetición y diferencia que asegura que nadie es aún completo o estable o fijado de una vez y para siempre) [... ] este juego sinfín de inestable llegar a ser en los niveles de la identi-

${ }^{24}$ Como un ejemplo, véase Rigney 2003.

${ }^{25} \mathrm{Su}$ concepción de los procesos sociales es derivado del pensamiento de E. Laclau y J. Derridá (Jenkins 2003, introd., pp. 3-4, y cap. 1). 
dad personal y política es la que posibilita políticas radicales desobediente contrahegémonicas y contradominantes. (Jenkins 2003, pp. 3-4)

Dado que ninguna posición puede ser legitimada sobre la base de cómo las cosas son realmente, dada la imposibilidad de realizar una clausura histórica total del pasado, debemos entonces figurar y refigurar el pasado asumiendo que tales presentaciones nunca serán suficientemente buenas. De allí su propuesta de refigurar el "antes de ahora historizado" en formas poco imaginadas y poco practicadas: "si algo podría sobrevivir bajo el nombre de historia entonces mejor sería la 'ficción útil' (en tanto veamos todas las historias como ficticias)" (Jenkins 2003, p. 6).

Podría pensarse que, en cierto sentido, Jenkins promueve la reescritura de la historia en formas que expresan el espíritu de mi trabajo: "toda la historia es historiografía (la acumulación de los escritos que conforman nuestras representaciones y presentaciones del pasado)" (Jenkins 2003, p. 11), denominando "refiguración" a este proceso propio de la práctica histórica. No obstante y a pesar de que a lo largo de su obra Jenkins ha reconocido su deuda con White, ha manifestado su simpatía con el pragmatismo rortyano y ha titulado su obra en abierta resonancia con el realismo figural, ${ }^{26}$ su lectura del realismo figural whiteano es contraria a las intenciones del propio White, pues no deja de ser una denuncia de la carencia de objetividad por parte del conocimiento histórico académico. En lugar de plantear una forma alternativa de concebir la historización, apropiándose de los desarrollos de la teoría literaria - como ha hecho White- y evitando la comparación con las ciencias naturales — con las que siempre sale perdiendo-, Jenkins se detiene a resaltar sus faltas, por lo que su propuesta de práctica histórica resulta pragmáticamente inconducente; esto es, admite como únicas alternativas de historización aquellas que o bien tienen pretensiones clausurantes, o bien que la interrumpen. Esta dicotomía no le permite vislumbrar una tercera alternativa: las que estimulan nuevas preguntas y visiones alternativas de mirar el pasado, las que se apropian de los desarrollos teóricos alternativos, e incluso de otras disciplinas, como recursos que desplegar.

En otras palabras, sus razones para promover la refiguración del pasado (reescritura, en nuestra terminología) derivan de una actitud parasitaria, dependiente de la historia académica denunciada como "objetivista". Podríamos preguntarle a Jenkins: sin historias efectuadas bajo

${ }^{26}$ Véanse las pp. 44-45 de Jenkins 2003.

Diánoia, vol. LI, no. 57 (noviembre 2006). 
un ideal de verdad y objetividad, ¿se darían buenas historias fracasadas? Su vocación por la refiguración desobediente del pasado pretende originarse en la autocrítica y el reconocimiento de que la hegemonía de hoy es el fracaso de mañana, su rechazo del pluralismo (asumido hoy por casi todos los historiadores) deriva de su acusación a los historiadores de no poder romper las cadenas que los esclavizan al deseo de alcanzar la clausura interpretativa. ${ }^{27}$ Ahora bien, esta reducción del pluralismo a la mera suma de interpretaciones intencionadamente clausurantes sólo puede emanar de una mala concepción de los discursos históricos y de la práctica historiográfica en general -muy poco pragmatista, por cierto-. Jenkins, como muchos narrativistas, en sus intentos de abandonar concepciones ingenuas de la relación entre discurso y realidad conciben, sin embargo, las interpretaciones como mónadas aisladas, descontextualizadas y acabadas. No perciben el carácter contextual y material de la producción interpretativa, el punto al cual el diálogo con otras interpretaciones - conflictivas o no-, así como la emulación de aplicaciones exitosas de otras disciplinas, se constituyen en recursos contribuyentes a la producción discursiva. Evitamos de este modo la ingenuidad de pensar que puede haber propuestas en abstracto de hacer historia. En lugar de arengar a subvertir la práctica porque sí, dando por descontado que es opresiva, ¿no sería más adecuado proponer subvertir ciertos relatos y utilizar la propia práctica como un recurso para ello? Nuestra aproximación heurística nos aconseja abordar el análisis de las interpretaciones historiográficas en su contexto de producción y recepción; este análisis es el que nos revela su carácter esencialmente polémico. Desde esta perspectiva y con este diagnóstico, la aproximación a cada obra histórica nos recomienda tener en cuenta otros trabajos sobre el tema, reseñas de ellos, información utilizada, e incluso desarrollos de otras disciplinas científicas o culturales; en definitiva, nos convoca a indagar las discusiones que motivó y las nuevas investigaciones a las que dio lugar. Más aún, la atención pragmática a la escritura (figuración) como reescritura (refiguración) del pasado posibilitará comprender que la práctica habitual de importar aplicaciones exitosas de otras disciplinas puede ser un recurso válido de subversión de relatos hegemónicos, dado que

${ }^{27}$ La noción de Martin 1998 de "divergencia interpretativa" manifiesta una clara superioridad heurística y pragmática frente a la de "desobediencia crítica". La primera se reconoce como la marca distintiva de la disciplina historiográfica, la cual, adecuadamente comprendida, puede darnos un criterio refinado de progreso historiográfico. La segunda, originada en un espíritu escéptico y una actitud parasitaria, muestra ser inútil para analizar las controversias historiográficas concretas. 
nuevamente rescata este aspecto material (no se puede inventar desde la nada) y nunca totalmente repetitivo de la producción de conocimiento. ${ }^{28}$

En su evaluación crítica sobre la historiografía académica, Jenkins no ha sabido distinguir entre un enfoque dirigido a evaluar las defensas teóricas explícitas de los historiadores acerca de su profesión -las cuales pueden coincidir con epistemologías realistas y naturalistas para todo conocimiento científico- y un enfoque que investigue la práctica histórica concreta, más allá de lo explícitamente sostenido por los protagonistas. Éste es el abordaje whiteano desplegado en Metahistoria, orientado a develar los recursos poético-estéticos de producción de interpretaciones historiográficas. ${ }^{29}$ Nuevamente, esta ceguera de enfoque ha hecho que Jenkins conserve de la teoría histórica de White la caracterización de la historia como ficción útil; mi apreciación, por el contrario, optó por desplegar la vía del realismo figural. La opción de Jenkins no da cuenta de cómo la retrospectiva, el disenso y la reescritura son vistos, desde una perspectiva pragmática, no como obstáculos para alcanzar el pasado tal cual fue, sino como actividades que contribuyen a promover la realización de más investigaciones. El realismo figural valora como historias heurísticamente mejores aquellas que, en su tal vez incumplida promesa de representar el pasado, al

${ }^{28}$ En Tozzi 2006b he ofrecido un detallado análisis con el objeto de mostrar que la aproximación de Browning a la comprensión de las motivaciones de los miembros del Batallón 101 de la Policía del Tercer Reich en sus sangrientas incursiones en la Europa del Este es heurísticamente superior a la de Goldgahen. Justamente, en su apropiación de los desarrollos de otras disciplinas y teorías ocupadas en la indagación de la conducta humana, así como el recurso a las interpretaciones de otros casos similares y la sugerencia de extender sus resultados a la comprensión de situaciones contemporáneas de perpetración, Browning instala efectivamente un programa de investigación con más cuestiones que indagar que respuestas definitivas y clausurantes (como sucedió en el caso de Goldhagen).

${ }^{29}$ Es pertinente recordar una vez más la recomendación kuhniana de comprender el conocimiento científico a partir del análisis de las prácticas concretas y de su historia. Quienes siguieron esta recomendación supieron apelar a la historia y la sociología de la ciencia para develar procesos de producción y legitimación científica, en analogía y comparación con la producción de otros fenómenos sociales y culturales, tal el caso de los Sociólogos de Edimburgo y su apelación a E. Gombrich y al segundo Wittgenstein, o de los amigos del descubrimiento (siendo Nickles su principal mentor), quienes, en la indagación de la posibilidad de una "lógica", "lógicas" o al menos de "reconstrucción racional" (pragmática) de la creación y el descubrimiento de nuevas teorías, inician estudios de casos de investigación. Ninguno ha supuesto que ello involucraba describir la práctica de los científicos en términos de sus motivaciones y creencias epistemológicas explícitas como deja entrever Jenkins.

Diánoia, vol. LI, no. 57 (noviembre 2006). 
dejar cuestiones abiertas renuevan no obstante su promesa de que, tal vez, alguna reescritura pueda lograr lo que no se alcanzó, por lo cual vale la pena seguir investigando. "Promesa de mejor representación, promesa nunca cumplida que promueve la investigación", ése sería mi eslogan. Por el contrario, Jenkins, con su festejo y estímulo de actitudes parasitarias para la práctica histórica, nos conduce al resultado irónico de que sus historias desobedientes, al no prometer nada, tampoco promueven la reescritura; en cambio, las supuestamente objetivistas sí.

\section{Los "privilegios" de la postergación}

Mi interés por contribuir a una apreciación pragmatista de la reescritura de la historia tiene una motivación específica: hacerme cargo de la agenda política de historizar el presente en respuesta a demandas de no olvido por parte de aquellos involucrados en sucesos de carácter traumático. En este punto debo expresar mi preocupación por la posibilidad, siempre latente, de que tras la intención de atender a las experiencias de los sujetos y escuchar sus voces se cuele un velado fundacionismo con consecuencias clausurantes, producto de otorgar privilegios epistémicos. Este potencial riesgo acecha también a White. En respuesta a los desafíos a la representación planteados por los acontecimientos traumáticos, White ${ }^{30}$ ha impulsado el rechazo de las formas académicas de escritura histórica típicas del siglo Xx. La historiografía profesional, en su intento de dar significado al Holocausto en términos de condiciones políticas, económicas o sociales, para mostrar su esperabilidad a partir del contexto, clausura su interpretación y obstruye la vuelta a repensarlo otorgando sentido a la experiencia de las víctimas como parte de un proceso mayor. La extremidad y peculiaridad de esa experiencia se ven así ahogadas en la corriente de la historia. La respuesta de White se apartará igualmente de aquellos que se llaman a silencio o a reproducir (como propone el cineasta Claude Lanzmann) testimonios de sobrevivientes. Fiel a su prescriptiva de buscar en la literatura los instrumentos de comprensión histórica, recomienda imitar el estilo literario modernista o el monólogo interior como la forma adecuada de representación de estas experiencias. Al mantener un tono de duda y perplejidad frente a lo que pasó, el monólogo interior evita, de este modo, distorsionar la persistente perplejidad y falta de sentido que

\footnotetext{
${ }^{30}$ Véase "El acontecimiento modernista", en White 2003a, pp. 217-252.
} 
experimenta la víctima acerca de lo que le sucedió. Su padecimiento no puede tener ningún sentido.

Comprometidos con la concepción realista figural de la representación histórica, la estrategia de White tiene la apariencia positiva de promover representaciones que persistan en la duda y la perplejidad para evitar que el suceso quede anclado en el pasado y sumido en el olvido. Sin embargo, si el tono de duda y perplejidad no se traduce en preguntas concretas que nos lleven a volver una y otra vez a ellos, que nos obliguen a verlos desde otro punto de vista, pensarlos de otra manera, persistiendo en volver dialógicamente, manteniendo abierta la disputa, nos arriesgamos a cometer el pecado que se quería evitar. La iteración literal de la experiencia traumática, el plantarse en la repetición del testimonio de las víctimas con el objeto de cancelar las típicas preguntas históricas - por qué sucedió, cómo fue posible, etc.- se presume un remedio contra las respuestas que eliminen la experiencia de la perplejidad. Sin embargo, a mi juicio esa estrategia de repetición monótona del testimonio es la que pone en riesgo que quede en el olvido, pues no sólo no promueve, sino literalmente clausura la reescritura histórica, única manera de mantener abiertas las preguntas que nos obliguen a volver a dichos sucesos. ${ }^{31}$

Encuentro, en Jenkins, una noción ciertamente sugestiva para nuestros propósitos, la de "experiencia historiográfica", la cual contribuiría a dilucidar la relación entre experiencia pasada y construcción histórica de una manera apreciable para una visión pragmatista. Sin embargo, en su enconada campaña por diagnosticar todo lo perniciosa que la historiografía académica es, Jenkins ha soslayado las consecuencias de esta noción, pues si le hubiera dado el lugar adecuado su diagnóstico sería distinto. Pregunta Jenkins: ¿hay algún sentido en que podemos "experimentar el pasado"?, ¿hay algún sentido en que podamos "experimentar el siglo XIII"? ${ }^{32}$ La respuesta a ambas preguntas es afirmativa sólo si evitamos pensar la cuestión literalmente y nos abrimos al sentido de tener experiencia o de contar con la presencia de las diversas presentaciones textuales del siglo XIII. Ahora bien, en lugar de desarrollar este abordaje "material" y colectivo de la experiencia como recurso disponi-

\footnotetext{
${ }^{31}$ He ejemplificado esta propuesta de recuperación heurística de los testimonios de las víctimas en el análisis de las demandas de los ex soldados argentinos ("chicos") de la Guerra de Malvinas, con el objeto de mostrar que el prejuicio del privilegio epistémico de las víctimas ha conducido a la sociedad argentina, paradójicamente, a ignorar sus reclamos por no concebir otra forma de intercambio. Véase Tozzi 2006c.

${ }^{32}$ Véase Jenkins 2003, p. 56.
} 
ble para la construcción de representaciones historiográficas, ${ }^{33}$ Jenkins la describe en contraste con la idea de experimentar el siglo XIII como lo haría un individuo del siglo trece; es decir, una vez más apuntando a la carencia, a la falta, a lo que nos está vedado. ${ }^{34}$ Vemos, justamente en este punto, una regresión de la hoy insoslayable crítica de Danto al Cronista Ideal.

Por último, quisiera evocar la evaluación de Koselleck del papel de la experiencia humana y personal en la investigación histórica por su cercanía a mi aproximación pragmatista. En un escrito titulado "Las transformaciones de la experiencia y cambio metodológico: un ensayo histórico-antropológico" 35 analiza y ejemplifica cómo diferentes experiencias históricas y cambios en la experiencia histórica han contribuido a cambios metodológicos en la disciplina. Dice Koselleck que hay un viejo principio que afirma que la historia es hecha por los vencedores; sin embargo, esto sólo puede mantenerse si adoptamos una perspectiva de mediano y corto plazo, focalizada en aquellos sucesos que los trajo a la victoria. Para el historiador alineado del lado de los perdedores, la experiencia primaria y contundente es que nada salió como se esperaba, y eso lo motiva a buscar en procesos más largos y estructuras más amplias las condiciones que limitaron la realización de los planes e intenciones humanos. "La experiencia de ser derrotado contiene un potencial epistemológico que trasciende su causa, especialmente cuando al derrotado se le exige reescribir la historia general en conjunción con la suya propia." ${ }^{36}$ La recomendación de Koselleck no debe ser leída en clave fundacionista, esto es, en el sentido de adoptar el punto de vista que nos da acceso a la realidad, sino como una recomendación metodológica de promocionar aquellos puntos de vista que estimulen más y más investigación.

Debo detenerme en este punto para señalar lo que considero una carencia en ciertos teóricos narrativistas por no haber tematizado la

${ }^{33}$ Pensemos la noción de Schütz (1995, p. 81) de la realidad social tal como es experimentada por el pensamiento de sentido común; es decir, socializado desde un principio: estructuralmente, ya que hay reciprocidad de perspectivas; genéticamente, porque es social su origen y su legitimación, y parcialmente distribuido, pues cada uno conoce un sector.

${ }^{34}$ Tengo en cuenta en este punto la distinción de Barry Barnes de causa material (otras creencias): el conocimiento se produce a partir del conocimiento anterior, y de causa final: hay un ideal de conocimiento al cual tienden nuestras creencias, aunque nunca se alcance; veáse Barnes 1977.

35 "Transformations of Experience, and Methodological Change: An HistoricalAnthropological Essay", en Koselleck 2002, pp. 45-83.

${ }^{36}$ Koselleck 2002, p. 77, las cursivas son mías.

Diánoia, vol. LI, no. 57 (noviembre 2006). 
noción de "experiencia histórica" o "experiencia del pasado". Éste es el caso específico de White, quien, adoptando un enfoque formalista, sólo se ha interesado por la relación del texto histórico con la realidad que pretende representar. Conforme con ello, no ha considerado pertinentes ni promisorios los estudios sobre la experiencia proporcionados por narrativistas fenomenológicos de la talla de David Carr y Paul Ricœur (o Barbara Hardy y Frederick Olafson). ${ }^{37}$ Estos autores han rastreado el origen de la forma narrativa del discurso histórico y del literario en la experiencia humana, personal y colectiva, de la temporalidad. ${ }^{38}$ Es más, White destaca de las investigaciones de Ricœur, en lo que se refiere a la configuración mimética, sólo aquellos aspectos que lo acercan a su propia posición e ignora todo lo que se refiere a la experiencia, de este modo se ha resistido a tomar en consideración reflexiones que permitan apreciar a la experiencia como construcción social y revisable, recurso insoslayable pero criticable, no totalmente subjetiva y producto de la interacción humana. Esta concepción más sofisticada de experiencia es la que podría ser recuperada desde una perspectiva pragmatista de la historización del pasado reciente, una noción tal de experiencia nos legitimará, además, para otorgar privilegio político a las experiencias de los postergados, pero sólo en cuanto voces insoslayables que nos obligan a investigar, revisar los discursos existentes y reescribir la historia que nos legan. Una perspectiva tal no necesita descansar en bases indudables, nos exime de conceder a esos reclamos el privilegio epistémico y nos convoca a sumarlos como otras voces en la promesa de reescribir el pasado reciente y evitar el olvido. ${ }^{39}$ No obstante mi crítica, debo señalar una importante diferencia entre White y Jenkins. El primero asume positivamente el perspectivismo histórico; es la mirada desde el presente lo que hace interesante el pasado, en ningún momento ha dejado entrever en ello una carencia o añoranza por no acceder a la perspectiva del contemporáneo.

Escuchar a los siempre postergados, mirar al pasado como lo mira un derrotado, no puede involucrar, en ninguna consideración histórica, otorgar un privilegio epistémico. Si la historia se ocupa de lo contingente, del cambio, y reconoce que la propia perspectiva desde la que

${ }^{37}$ White $2003 a$, pp. 177-178.

${ }^{38}$ Sobre todo Carr y Ricœur, quienes siguiendo el análisis husserliano del horizonte protencional-retencional, develan la estructura de la experiencia como no reducible a una sucesión lineal de instantes.

${ }^{39}$ En el tema de la noción de experiencia histórica, más que promover la adopción de una u otra tradición, lo que quiero reclamar es la falta de diálogo entre ellas en lo que respecta a este punto.

Diánoia, vol. LI, no. 57 (noviembre 2006). 
mira el pasado es contingente y cambiante, tal como todos los autores estudiados en este trabajo, y White más que nadie, han contribuido a elucidar, no puede esperarse que ninguna perspectiva nos oriente privilegiadamente en la producción y elección de representaciones. Pero, como ya dije, la carencia de perspectivas privilegiadas no es algo por lo que nos tengamos que amargar. Una lectura pragmatista del realismo figural explica, a mi juicio, por qué no puede haber, ni debería haber, una visión privilegiada para representar los acontecimientos históricos; por el contrario, nos obliga a ser críticos y a estar alerta frente a todo intento de donar privilegios epistémicos a víctimas o perdedores, del mismo modo que no se los otorgamos a tiranos y vencedores. La concepción realista figural de la historización, aplicada a la representación de sucesos recientes, nos ofrece el antídoto contra el olvido a que nos arriesgan las clausuras interpretativas de la historia, pues se opone a aquellas actitudes que, pretendiendo reivindicar experiencias soslayadas, contingente y arbitrariamente, congelan alguna imagen de ellos, obstaculizando, de este modo, la aparición de nuevas y más prometedoras representaciones que contribuyan a su elaboración crítica. En conclusión, la promesa incumplida de representación definitiva no es otra cosa que la sugerencia de nuevas vías de investigación, de nuevos problemas, nuevas discusiones y, quizás, con buena fortuna, una nueva reescritura del pasado.

\section{BIBLIOGRAFÍA}

Ankersmit, F. R., 2003, "Danto, History, and the Tragedy of Human Existence", History and Theory, Studies in the Philosophy of History, vol. 42, no. 3, pp. 291-305.

_- 2001, Historical Representation, Stanford University Press, Stanford.

_ 1986 , "The Dilemma of Contemporary Anglo-Saxon Philosophy of History", History and Theory, Studies in the Philosophy of History, suplemento 25, Knowing and Telling History. The Anglo-Saxon Debate, pp. 1-27.

Auerbach, E., 1950, Mimesis: La representación de la realidad en la literatura occidental, trad. J. Villanueva y E. Imaz, Fondo de Cultura Económica, México (1a. ed. en alemán: 1942).

Barnes, B., 1977, Interest and the Growth of Knowledge, Routledge, Londres.

Danto, A., 1989, "Oraciones narrativas", en Historia y narración, introd. y trad. Fina Birulés, Paidós, Barcelona, pp. 99-155 (corresponde al cap. 8 de Analytical Philosophy of History, Cambridge University Press, Cambridge, 1965; también incluido en Danto 1985).

_, 1985, Narration and Knowledge, Columbia University Press, Nueva York (incluye la versión completa de Analytical Philosophy of History, aparecida en 1968). 
Friedlander, S. (ed.), 1992, Probing the Limits of Representation: Nazism and the "Final Solution", Harvard University Press, Cambridge.

Jenkins, K., 2003, Refiguring de Past, Routledge, Londres/Nueva York.

Koselleck, 2002, The Practice of Conceptual History. Timing History, Spacing Concepts, Stanford University Press, Stanford.

— 1993 , Futuro pasado. Para una semántica de los tiempos históricos, trad. Norberto Smilg, Paidós, Barcelona.

LaCapra, D., 2001, Writing History, Writing Trauma, The Johns Hopkins University Press, Baltimore/Londres.

Martin, R., 1998, "Progress in Historical Studies?", History and Theory. Studies in the Philosophy of History, vol. 37, no. 1, pp. 14-39.

Mink, L., 1987, Historical Understanding, ed. Fay, Golob y Vann, Cornell University Press, Ithaca.

Nickles, T., 1989, "Heuristic Appraisal: A Proposal”, Social Epistemology, vol. 3, no. 3, pp. 175-178.

Rigney, A., 2003, The Rhetoric of Historical Representation: Three Narrative Histories of the French Revolution, Cambridge University Press, Cambridge (1a. ed.: 1991).

Schütz, 1995, El problema de la realidad social, 2a. ed., Amorrortu, Buenos Aires.

Tozzi, V., 2006a, "Historia y representación social del trauma", incluido en una compilación de Elisa Carrió y Diana Maffia (en prensa).

— 2006 b, "Evaluación heurística en la historiografía. El debate BrowningGoldgahen", en G. Klimovsky (comp.), Los enigmas del descubrimiento científico, Alianza, Buenos Aires, pp. 185-206.

- , 2006c, "Apuntes sobre Malvinas. Tragedia y limbo mnémico en el encuentro con el pasado reciente", en Cecilia Macón (coord.), Pensar la democracia, imaginar la transición (1976-2006), Ladosur, Buenos Aires, pp. 83-98.

Tozzi, V. y Cecilia Macón, 2005, "El acontecimiento extremo: experiencia traumática y disrupción de la representación histórica”, en D. Brauer y M. Cruz (comps.), La comprensión del pasado, Herder, Barcelona, pp. 111-132.

Walsh, W., 1968, Introducción a la filosofía de la historia, Siglo XXI, México (1a. ed. en inglés: 1961).

White, H., 2003a, El texto histórico como artefacto literario, trad. Verónica Tozzi y Nicolás Lavagnino, introd. Verónica Tozzi, Paidós, Barcelona.

—, 2003 b, "Teoría literaria y escrito histórico", en White 2003a, pp. 141188.

_, 1999a, Figural Realism, Studies in the Mimesis Effect, The Johns Hopkins University Press, Baltimore.

—, $1999 b$, "Auerbach's Literary Theory. Figural Causation and Modernist Historicism", en White 1999a, pp. 87-100.

— Fondo de Cultura Económica, México (1a. ed. en inglés: 1973).

Recibido el 15 de agosto de 2005; aceptado el 7 de abril de 2006.

Diánoia, vol. LI, no. 57 (noviembre 2006). 